\title{
AC 2010-152: WHAT E-COMMERCE KNOWLEDGE TOPICS ARE CRITICAL FOR SOFTWARE ENGINEERS: A JOINT ACADEMIC/INDUSTRY INVESTIGATION IN TAIWAN
}

Yi-Cheng Chen, Meiho Institute of Technology

Yi-Chien Lin, Meiho Institute of Technology

Ron Chuen Yeh, Meiho Institute of Technology, Taiwan

Kuo-Hung Tseng, Meiho Institute of Technology 


\title{
What E-Commerce Knowledge Topics Are Critical for Software Engineers: A Joint Academic/Industry Investigation in Taiwan
}

\begin{abstract}
The fast-paced developments in electronic commerce (e-commerce, EC) technologies have largely changed the landscape of both the established and emerging commercial world. Software engineers must cope with the dramatic challenges in today's business environment. Facing more severe pressure in allocating a firm's e-resources, they should possess proficient skills/knowledge to find more effective and efficient approaches for solving business problems. This is the great challenge in the software engineering (SE) discipline. There might be great impacts occurring in the teaching and learning in the SE education sector. In this study, we empirically investigated what EC knowledge topics are critical for software engineers in Taiwan. More than 150 software engineers participated in this study to provide what they thought about 28 e-commerce knowledge topics. The respondents were asked to rate the knowledge level that they had learned about each of the course in their formal education, are now familiar with about it as well as how practical the topic will be in their career. The research findings may be instrumental for e-commerce training programs, licensing bodies, departments and curriculum designers in field of software engineering. The results of this study can provide useful suggestions to help software engineers for selecting the suitable and right learning courses as well as to act as practicable guidelines for EC curriculum planning and development.
\end{abstract}

Keywords: software engineer, e-commerce, EC education, curriculum development, knowledge topic

\section{Introduction}

With the invention of World Wide Web (WWW) by 1990, the global network is applied to variety of domains. The digital economy era has been merging in global industries with unprecedented challenges; therefore, implementation of information technology has become an important role in promoting core competition for industries or governments and no doubt will has great impacts upon economy growth rate in the future. Further more, electronic commerce has been starting to develop flourishingly from 1998, and thus, trading between business types and consumers has been changing step by step.

Information technology (IT) applications in the business environment have changed and continue to change dramatically (Benamati \& Lederer, 2001; Tennyson, 2001; Wu et al., 2004). Facing these emerging ITs, software engineers need to make difficult choices and then implement, deliver, and support these choices throughout their organizations. Through those steps force IS educators, instructional technologists and practitioners to reevaluate and acquire compulsory knowledge, skills, and abilities as a regular basis (King, 2002). On the other hand, regarding the promotion of electronic commerce, firstly, development of electronic commerce is based on fundamental facilities of the internet in order to ensure rapid application to trading among enterprises or between enterprises and consumers. Secondly, there are professional legal issues involved such as protection of intellectual property rights, the right to privacy and taxing. 
However, training electronic commerce (e-commerce, EC) talents as a matter of great urgency is a top priority solution to aforementioned problems. As a result, institutes for training EC-related human resource were set up rapidly and massively, particularly in college and university education. In this report, it will explore not only EC education of college and universities in Taiwan but also understanding and information of EC implementation in the business industry.

Hence, cultivating university/college-level students majoring software engineering with the required information literacy regarding EC education and providing them state of the art EC course topics to sustain the organization effectively is becoming a great challenge to the relative stakeholders such as IS training educators, departments administrators and curriculum designers (Lee et al., 1995; Milliken \& Barnes, 2002). To address the above challenges, this study investigated what topics are important to software engineer from the business enterprises in Taiwan. A survey instrument was developed to answer the questions: how much these practitioners had learned about the topic in their formal educations, how much they know now about the topic and how important the topic has been in their career.

\section{The Evolution of Computing Technologies and EC Education in Taiwan}

In recent years, the recognized shifts in information and communication technologies (ICTs) have taken place from Web-based computing, mobile computing, to ubiquitous computing (Wu $\&$ Hisa, 2004). These principal ICT directly enabling modern E-commerce include Web-based computing, mobile computing, and ubiquitous computing (Banavar \& Bernstenin, 2002; Kannan et al., 2001; Samaras, 2002). The Web-based computing was implemented based on a wired network using the Internet until the ability to connect started approaching physical limit-mobility. The mobile computing based on wireless infrastructure gave rise to a new $\mathrm{S}$ curve, with the new physical limits being a higher level of ubiquity and embeddedness (Lyytinen \& Yoo, 2002). Over the past decade, we have witnessed the rapid developments in ICT which have substantially changed the landscape of E-commerce. The Internet has introduced a significant wave of change. Our communication patterns have changed.

E-commerce (EC) is based not only on developments pertaining to the Internet compound, but also on prior technological and organizational innovation arising from the combinations of telecommunications and network computing (Zwass, 2003). We have become dependent on Internet. We interact with firms via Web sites. The proliferation of Internet has stimulated the development of online commercial applications and business innovations, commonly referred to Internet-enabled commerce (I-commerce). The next wave - introduced through mobile technology - is about to change our lives and business world even more. The increase in transmission capacity of wireless devices lays the foundation for transaction unrestricted by physical locations. We can do transformation any time, blurring the borderlines of business and private space. The enabling E-commerce form is called as mobile commerce (M-commerce) (Varahney et al., 2000, Balasubramanian et al., 2002). Recently, many experts have proposed another wave of change - a world that provides the ultimate form of ubiquitous networks and universal devices, a world that presents an alternative view of space and time (Fano \& Gershman, 2002; Islam \& Fayad, 2003). Likewise, we will enter into a new context of E-commerce - a form that goes over, above, and beyond traditional commerce. The emerging frontier for E-commerce is ubiquitous commerce (U-commerce) (Watson, et al., 2002). 
New ICT applications often are in conjunction with organizational changes (Markus, 2004). Indeed, the rapid evolution of E-commerce: from I-commerce, M-commerce to U-commerce poses considerable challenges for many firms and results in many new change management issues. For incumbent firms, the main challenge is change (Wheeler, 2002, Daniel \& Wilson, 2003). Innovative E-commerce applications, however, have the potential for significant changes in ICT applications and in firm's business model and performance - and the potential for all kinds of disruption for the E-commerce stakeholders. To cope with the changes, a number of researchers have suggested that it is vitally important for firms to understand the dynamics and nature of change and how to manage it well (Straub, 2001; Markus, 2004). Therefore, a systematic study of E-commerce education is needed in Taiwan.

From 1998 on, commerce automation research and development centers were set up by Ministry of Education in National Taipei University, Dayeh University, National Yunlin University of Science \& Technology, and National Sun Yat-sen University, respectively in the south, the midland, and the north of Taiwan. By integrating intramural, cross-campus, and industrial academic resource, research and educational achievements, commerce automation were popularly promoted. In Taiwan, undergraduate and graduate schools of commerce automation were instituted in few colleges, and most of colleges have commerce automation programs. Statistic data in 1998 from Ministry of Education showed that there were 110 instructors of professional faculty including six professors, 76 associate professors, six assistant professors and 22 lecturers from departments of information management and departments of business management. With completing a phased mission of ten-year production automation project by 2000, Taiwan-Ministry of Education made a plan of educational development in integration of emanufacturing and e-commerce to operate in coordination with a scheme of production automation and e-business carried out by The Executive Yuan in order to educate talents for logistics, cash flow, business flow, service flow, and information flow. Further more, there were three EC-related graduate institutes and three undergraduate programs of e-commerce in colleges and universities by 2007 in Taiwan. Afterward, 103 colleges and universities had departments of information management, EC-related programs in 75 schools. Up to 2009, ten colleges and universities set up EC-related programs such as electronic commerce (management), information commerce, and information management in National Chung Hsing University, Tatung University, Nan Hua University, Aletheia University, Wu Feng Institute of Technology, etc.

Comprehensively understanding education development of business automation in Taiwan, many colleges and universities focus on establishing of EC teaching environments. A report regarding improvement of commercial automation instruction by Taiwan-Ministry of Education indicated that most of colleges have started to plan and establish e-commerce educational environments. In addition, they pondered on how to fit the internet properly in management courses. For examples, Dayeh university and National Yunlin University of Science \& Technology set up electronic stores; National Taiwan University of Science \& Technology has done the completion of building website of e-commerce instruction; and Feng Chia University built professional commercial website for supply information about insurance and finance. There are several practical strategies of e-commerce education in Taiwan organized as follows:

1. To establish e-commerce lab or e-commerce center for facilitating relevant research and education in e-commerce. 
2. To coordinate faculty and facilities of relevant courses and plan e-commerce programs.

3. To set up campus electronic stores for providing opportunities for students to have practical experiences.

4. To build websites of EC-related instruction and database for improving experience communication.

5. To edit kinds of e-commerce teaching materials such as books and multimedia, and ensure the share-ability of teaching materials.

6. To hold e-commerce competitions, workshops, and educational training.

\section{Research Design}

This study takes account of the characteristics of EC related courses in Taiwan, and gathers the information about EC curriculum planning in well-known universities in Taiwan (e.g., National Sun Yat-Sen University). We reviewed the related EC research literature and recommended Association for Computing Machinery (ACM) curriculum documents, such as IS 2002, "model curriculum and guidelines for undergraduate degree programs in information systems", CC2005, "the overview report including the guide to undergraduate degree programs in computing", and MSIS 2000, "model curriculum and guidelines for graduate degree programs in information systems" to find out critical EC knowledge topics which are critical for university-level Ecommerce education in Taiwan. Based on the intensive literature review and several rounds of in-depth interviews with domain experts, $28 \mathrm{EC}$ knowledge topics were identified to form the scales as shown in Table1.

Table 1. The Classification and Related EC Course Topics in This Study

\begin{tabular}{llll}
\hline Category & \multicolumn{1}{c}{ IT Specific } & \multicolumn{1}{c}{ IT-Business Integration } & \multicolumn{1}{c}{ Management } \\
\hline & 1.Introduction to Computer & 1.Introduction to Information & 1.Knowledge Management \\
& Science & Management & 2.Project Management \\
& 2.Programming Languages & 2.Systems Analysis \& Design & 3.Marketing Management \\
& 3.Database Management & 3.Information Security & 4.Production and Operation \\
EC Related & Systems & 4.e-Commerce & Management \\
Knowledge & 4.Operating Systems & 5.Information Systems Planning & 5.Information Ethics \\
Topics & 5.Data Communication \& & 6.Enterprise Resource Planning & 6.Human Resource \\
& Internetworking & 7.Decision Support Systems & Management \\
& 6.Data Mining & 8.Supply Chain Management & 7.Strategic Management \\
& 7.Multimedia Systems & 9.Production Information Systems & 8.Financial Management \\
& 8.Wireless Communication & 10.Strategic Information Systems & 9.Innovation Management \\
& Network & 11.Accounting Information Systems & \\
\hline
\end{tabular}

A survey instrument of EC knowledge topics was developed and used to collect the data in this study. Data were gathered by researchers in personal interviews with IS/IT practitioners and academic experts using the questionnaire to structure their questions. From this, the researchers were able to gauge the clarity of the notations presented, assess whether the instrument correctly reflected real phenomenon desired by the researchers, and verify if any important EC knowledge topics were omitted. This process was continued until no further modifications to the questionnaire were necessary. Feedbacks from this pilot study served as the basis for refining the experimental scales of the course items. The researchers tested and revised the questionnaire several times before starting to gather the data.

The questionnaire contained 2 major parts including respondent's basic data portion and the responses to EC knowledge topics. The basic data portion requested IS/IT practitioners to give 
the names of their organizations and main tasks and needed demographic characteristics and fill out their current management position of the subject. The second part contained 28 course topics and each topic associated with four of the following questions adopted from Lethbridge (1998) to capture subject's perception on each course topic as follows:

- Q1. Amount learned in education (i.e., How much did you learn about this in your formal education?)

$0=$ Learned nothing at all

$1=$ Became vaguely familiar

$2=$ Learned the basics

3 = Become functional (moderate knowledge)

$4=$ Learned a lot

$5=$ learned in depth; become expert

- Q2. Amount learned on the job: What is your current knowledge about this, considering what you have learned on the job as well as forgotten?

$0=$ know nothing

$1=$ Am vaguely familiar

$2=$ Know the basics

$3=$ Am functional (moderate knowledge)

$4=$ Know a lot

$5=$ Know in depth; become expert

- Q3. Practical level: How useful have the details of this specific material been to you in your career as a professional IS staff or manager? Please leave blank if you know little about the material.

$0=$ Completely useless

$1=$ Almost never useful

2 = Occasionally useful

$3=$ Moderately useful (only in certain activities)

$4=$ Very useful

$5=$ Essential

- Q4. Influence level: How much influence has learning the material had on your thinking (your approach to problems and your general intellectual maturity), whether or not you have used the details of the material? Please consider influence on both your career and other aspects of your life. Please leave blank if you know little about the material.

$0=$ No influence at all

$1=$ Almost no influence

$2=$ Occasional influence

$3=$ Moderate influence in some activities

$4=$ Significant influence $n$ many activities

$5=$ Profound influence on almost everything I do

Responding software engineers participated in this study were from various types of industries using a questionnaire survey administered in Taiwan. Enterprises from the Top-1000 firms ranked by Taiwan's Bureau of business were included. Only those firms with a formal MIS department were qualified to be selected. Through a random sampling procedure, 500 companies from the Top-1000 firms were selected at random for constituting a representative sample in this 
study. Each company received an initial phone call explaining the purpose of this research project and inquiring about the firm's willingness to participate in this study. Participation in this study was voluntary and respondents were assured that their individual responses would be treated as confidential. A follow-up phone call was used to increase the response rate. We sent out 1000 questionnaires to the software engineers and received 225 returned questionnaires. Invalid responses were discarded. Then, the left 160 valid responses were then coded for statistical analysis. Among them, most respondents work on IS related jobs in a diversity of industries; analysis results show that only 14 percent of the respondents do not work in IS related departments. 70.6 percent had received a bachelor's degree and 22.5 percent had postgraduate degrees. More than 70 percent of the respondents had their final degrees in computer science, software engineering, or information systems; while 24 percent had degrees in other areas of science, engineering or discipline.

\section{Data Analysis and Results}

As mentioned previously, the $28 \mathrm{EC}$ related knowledge topics were classified into three categories including "IT specific", "IT-Business integration" and "management" types of course topics to facilitate locating topics and to help the interpretation of results. Tables 2 and 3 summarize the important results concerning the knowledge levels and the overall importance of the course topics as perceived by the respondent of software engineers in Taiwan.

\section{EC Related Course Topics Software Engineers Learned in Education}

For each EC related course topic, the amount learned in education was calculated from the average of the responses to Question1. The top five most extensively taught topics are "Introduction to Computer Science", "Programming Language" and "Database Management Systems" in IT specific category, as well as "Introduction to Information Management" and "Systems Analysis \& Design" in IT-Business integration category. There are one IT-specific course of "Wireless Communication Network", one IT-Business integration course of "Accounting Information Systems" as well as three management related courses, "Innovation Management", "Financial Management", and "Strategic Management" that the participants learned the least in their formal education. As a whole, the amount learned data implies the extent to which each course had been taught in educational institutions. Table 2 organized these topics by the rank of the amount of each course learned to give valuable information to educators and curriculum designers concerning the knowledge learned most and least by the software engineers in their formal education.

\section{Current Knowledge Levels on EC Related Course Topics of Software Engineers}

The responses to Question 2 provide the amount of what software engineers currently knew about. Table 2 also shows the top five topics of the respondents' current knowledge level which are almost the same as the top five most learned topics in education except for "Data Communication \& Internetworking" in IT-specific category. Conversely, while some of the orders of courses are slightly different, the least five important topics of the respondents' current knowledge level are almost the same as the least five important learned topics in education. The current knowledge data suggests what sorts of EC knowledge topics that software engineers are 
now proficient and deficient on in the industry. The five courses of "Strategic Information Systems", "Accounting Information Systems", "Strategic Management", "Financial

Management", and "Innovation Management" seem to be ignored by the majority of Software engineer in the industry in Taiwan. The practicability and the popularity of these courses perceived less important might be task-oriented and industry specific.

Table 2. Ranks of Software Engineers' Knowledge Levels on EC Course Topics

\begin{tabular}{|c|c|c|c|c|c|c|c|}
\hline \multirow{4}{*}{ Category } & \multirow{4}{*}{ EC related knowledge topic } & \multicolumn{2}{|c|}{$\begin{array}{c}\text { Learned* } \\
\text { in education }\end{array}$} & \multicolumn{2}{|c|}{$\begin{array}{c}\text { Current } \\
\text { knowledge }\end{array}$} & \multicolumn{2}{|c|}{$\begin{array}{l}\text { Learned } \\
\text { on the job }\end{array}$} \\
\hline & & \multicolumn{6}{|c|}{ Top ( ) and bottom ( ) five courses, in terms of: } \\
\hline & & \multicolumn{2}{|c|}{ Q1 } & \multicolumn{2}{|c|}{ Q2 } & \multicolumn{2}{|c|}{ Q2 - Q1 } \\
\hline & & Mean & Rank & Mean & Rank & Mean & Rank \\
\hline \multirow{8}{*}{ IT Specific } & Introduction to Computer Science & 3.1 & 10 & 3.27 & 10 & 0.17 & 28 \\
\hline & Programming Languages & 2.71 & 20 & 3.19 & 20 & 0.48 & 18 \\
\hline & Database Management Systems & 2.6 & 30 & 3.14 & 30 & 0.54 & 13 \\
\hline & Operating Systems & 2.57 & 6 & 2.98 & 7 & 0.41 & $24 \bullet$ \\
\hline & Data Communication \& Internetworking & 2.56 & 7 & 3.07 & 50 & 0.51 & 16 \\
\hline & Data Mining & 1.43 & 18 & 1.89 & 20 & 0.46 & 20 \\
\hline & Multimedia Systems & 1.43 & 19 & 1.89 & 21 & 0.46 & 21 \\
\hline & Wireless Communication Network & 1.21 & 250 & 1.93 & 19 & 0.72 & 6 \\
\hline \multirow{12}{*}{$\begin{array}{l}\text { IT-Business } \\
\text { Integration }\end{array}$} & Introducation to Information Management & 2.6 & 40 & 3.03 & 6 & 0.43 & 23 \\
\hline & Systems Analysis \& Design & 2.59 & 50 & 3.13 & 40 & 0.53 & 15 \\
\hline & Information Security & 1.93 & 8 & 2.69 & 9 & 0.77 & 30 \\
\hline & e-Commerce & 1.84 & 9 & 2.61 & 10 & 0.76 & 40 \\
\hline & Information Systems Planning & 1.81 & 11 & 2.7 & 8 & 0.89 & 20 \\
\hline & Enterprise Resource Planning & 1.77 & 12 & 2.48 & 11 & 0.71 & 7 \\
\hline & Decision Support Systems & 1.55 & 15 & 2.09 & 16 & 0.54 & 14 \\
\hline & Supply Chain Management & 1.46 & 17 & 2.08 & 17 & 0.62 & 10 \\
\hline & Production Information Systems & 1.33 & 21 & 2.23 & 14 & 0.9 & 10 \\
\hline & Strategic Information Systems & 1.27 & 23 & 1.74 & 250 & 0.47 & 19 \\
\hline & Accounting Information Systems & 1.11 & 270 & 1.79 & 240 & 0.68 & 8 \\
\hline & Knowledge Management & 1.83 & 10 & 2.4 & 13 & 0.58 & 11 \\
\hline \multirow{9}{*}{ Management } & Project Management & 1.71 & 13 & 2.47 & 12 & 0.76 & 50 \\
\hline & Marketing Management & 1.6 & 14 & 2.01 & 18 & 0.41 & 250 \\
\hline & Production \& Operation Management & 1.54 & 16 & 2.21 & 15 & 0.66 & 9 \\
\hline & Information Ethics & 1.38 & 20 & 1.79 & 23 & 0.41 & 260 \\
\hline & Human Resource Management & 1.31 & 22 & 1.88 & 22 & 0.58 & 12 \\
\hline & Strategic Management & 1.26 & 240 & 1.71 & 260 & 0.44 & 22 \\
\hline & Financial Management & 1.2 & 260 & 1.7 & 270 & 0.5 & 17 \\
\hline & Innovation Management & 0.82 & 280 & 1.14 & 280 & 0.33 & 270 \\
\hline & Introduction to Computer Science & 3.1 & 10 & 3.27 & 10 & 0.17 & 280 \\
\hline
\end{tabular}

*Ordered by the rank of learned in education in each category

\section{EC Related Course Topics Software Engineers Learned on the Job}

The amount learned on the job (or forgotten since education) is the difference between the amount currently known and the amount learned in education (i.e., the response to Question 1). As shown in Table 2, the top five most learned topics from software engineers' job experience are "Production Information Systems", "Information Systems Planning", "Information Security", and "e-Commerce" in IT-Business integration category, and "Project Management" in 
Management category. It is quite reasonable because software engineers can acquire experience and learn much more on these courses by doing their jobs than taking these courses in school. On the contrary, regarding the five IT-specific courses including, "Artificial Neural Networks", "Artificial Intelligence", "Fuzzy Theory", "Computer Visualization", and "Introduction to Computer Science", the participants deemed they have learned the least from their job experiences. This bolsters our argument for reexamining coverage and teaching methods for these topics to improve the educational investment return.

Table 3. Ranks of the Overall Importance of EC Course Topics

\begin{tabular}{|c|c|c|c|}
\hline \multirow{4}{*}{ Category } & \multirow{4}{*}{ EC Course Topic } & \multicolumn{2}{|c|}{ Overall importance* } \\
\hline & & \multirow{2}{*}{\multicolumn{2}{|c|}{$\begin{array}{c}\text { Top }(\mathbf{O}) \text { and bottom }(\mathbf{)}) \text { five } \\
\text { courses, in terms of: } \\
\text { Avg. }(\mathrm{Q} 3, \mathrm{Q} 4)\end{array}$}} \\
\hline & & & \\
\hline & & Mean & Rank \\
\hline \multirow{8}{*}{ IT Specific } & Database Management Systems & 3.54 & 20 \\
\hline & Programming Languages & 3.51 & 30 \\
\hline & Data Communication \& Internetworking & 3.46 & 40 \\
\hline & Introduction to Computer Science & 3.18 & 8 \\
\hline & Operating Systems & 3.16 & 9 \\
\hline & Wireless Communication Network & 2.43 & 17 \\
\hline & Data Mining & 2.35 & 19 \\
\hline & Multimedia Systems & 2.01 & $27 \oplus$ \\
\hline \multirow{11}{*}{$\begin{array}{l}\text { IT-Business } \\
\text { Integration }\end{array}$} & Systems Analysis \& Design & 3.55 & 10 \\
\hline & Introducation to Information Management & 3.43 & 50 \\
\hline & Information Security & 3.31 & 6 \\
\hline & Information Systems Planning & 3.19 & 7 \\
\hline & Enterprise Resource Planning & 3.02 & 10 \\
\hline & E-Commerce & 2.83 & 13 \\
\hline & Supply Chain Management & 2.66 & 14 \\
\hline & Production Information Systems & 2.5 & 16 \\
\hline & Decision Support Systems & 2.41 & 18 \\
\hline & Accounting Information Systems & 2.29 & 21 \\
\hline & Strategic Information Systems & 2.19 & 23 \\
\hline \multirow{9}{*}{ Management } & Project Management & 2.93 & 11 \\
\hline & Knowledge Management & 2.87 & 12 \\
\hline & Production \& Operation Management & 2.58 & 15 \\
\hline & Marketing Management & 2.3 & 20 \\
\hline & Human Resource Management & 2.21 & 22 \\
\hline & Information Ethics & 2.15 & 240 \\
\hline & Financial Management & 2.11 & $25 \theta$ \\
\hline & Strategic Management & 2.02 & $26 \theta$ \\
\hline & Innovation Management & 1.69 & $28 *$ \\
\hline
\end{tabular}

*Ordered by the rank of overall importance in each category.

\section{Overall Importance of EC Related Course Topics}

The responses of each EC related knowledge topic to Questions 3 and 4 provide the amount perceived in overall importance data. The importance of each topic was computed by averaging the responses to questions 3 and 4. The relative ranking of the top five most important and five least important topics are shown in Table 3, respectively. The results signify that the respondents 
consider "System Analysis \& Design" to be the most important topic, with "Database Management Systems" close behind, followed by "Programming Language", "Data Communication \& Internetworking", and "Introduction on Information Management". The majority of the top five most important topics are all fundamental compulsory courses for IS departments in the universities and colleges in Taiwan. The descriptive results also show that the least five important topic is "Innovation Management", followed by "Multimedia Systems", "Financial Management", "Financial Management", and "Strategic Management". All of the 5 least important topics are interest-oriented elective courses in the universities and colleges in Taiwan. The practicability of these courses might be job-oriented and industry specific.

\section{Discussion and Conclusion}

This study aims at investigating what EC knowledge topics are critical for software engineers from a joint academic/industry perspective in Taiwan. The results provide interesting insights into the EC related course topics among overall importance, education and current known. In order to make the study more complete, we conducted a series of follow-up interviews with 12 responding software engineers with most knowledge "learned in education", and 12 respondents with most knowledge "learned on the job". Also, we compared the curriculum of IT department of a well-know vocational college in the southern part of Taiwan and interview the relevant faculty of the IT department who are currently teaching the related EC-related topics to rigorously justify our research results.

All of the interviewees including the relevant faculty members asserted that the findings in this study regarding the knowledge levels of each course can accurately reflect the real condition in the industry. All of them also indicated that the educational knowledge gaps of university-level EC education may still exist between industry expectation and academic preparation in Taiwan. They all worry about the impacts caused by the gaps and provide invaluable suggestions without reservations. They indicated that education sectors should either place less emphasis on the topics or teach them in a way that makes them more relevant to students because of the low importance and highly forgotten courses. Twelve of the group members with most knowledge "learned in education" emphasized that education sectors should offer more intern opportunities for the practices of courses. There were 15 interviewees in managerial levels and they suggested that educational institutions should place more emphases on the fundamental courses to cultivate students with essential skills/knowledge and capabilities to cope independently with highly changeable business environment.

On the other side, some of the interviewed faculty members of the IT department signified that university-level IT education should emphasize more on an in-depth knowledge of how emerging EC technologies can be applied by business firms as well as an in-depth understanding of databases management systems, systems analysis and design, implementation, integration and management issues. The comparison between the IT curriculum and the survey results shows that many of the important topics were not extensively taught, for example, Information Security, Information Systems Planning, Enterprise Resource Planning, Wireless Communication Network and Project Management. Universities might consider increasing their coverage of such topics and the education or training departments in firms might provide the relevant knowledge topics. 
By and large, this study has several implications for formulation of EC educational training programs or EC curriculum for universities/colleges in Taiwan. The findings of this study might be supportive to EC training institutes, licensing bodies, departments and curriculum designers in universities or colleges. Software engineering students, graduates, and professionals in EC related field who are seeking continuing education and on the job training will also be able to use the results of this study to help selecting the suitable EC course topics for their future career planning.

\section{Reference}

1. Balasubramanian S., Peterson, R .A and Jarvenpaa, S. L., "Exploring the Implications of M-Commerce for Markets and Marketing," Journal of the Academy of Marketing Science, 30(4), 2002, pp. 348-361.

2. Banavar, G. and Bernstein, A., "Software Infrastructure and Design Challenges for Ubiquitous Computing Applications," Communications of the ACM, 45(12), 2002, pp. 92-96.

3. Benamati, J. and Lederer A. L., "Coping with Rapid Changes in IT", Communications of the ACM, 44(8), 2001, pp.83-88.

4. Daniel, E. M. and Wilson, H. N., "The Role of Dynamic Capabilities in E-Business Transformation," European Journal of Information Systems, 12(3), 2003, pp. 282-296.

5. Fano, A. and Gershman, A., "The Future of Business Services in the Age of Ubiquitous Computing," Communications of the ACM, 45(12), 2002, pp. 63-87.

6. Islam, N. and Fayad, M., "Toward ubiquitous acceptance of ubiquitous computing," Communications of the ACM, 46(12), 2003, pp. 89-92.

7. Kannan, P. K., Chang, A. M., and Whinston, A. B., "Wireless Commerce: Marketing Issues and Possibilities," The 34th Hawaii International Conference on System Sciences, 2001.

8. King, K. P., "Educational Technology Professional Development as Transformative Learning Opportunities", Computers \& Education, 39(1), 2002, pp. 283-297.

9. Lee, D.M.S., Trauth, E.M. and Farwell, D., "Critical Skills and Knowledge Requirements of IS Professionals: A Joint Academic/ Industry Investigation”, MIS Quarterly, 19(3), 1995, pp. 313-340.

10. Lee, S., Koh S., Yen, D. and Tang, H. -L., "Perception Gaps between IS Academics and IS Practitioners: An Exploratory Study", Information \& Management, 40(1), 2002, pp.51-61.

11. Lethbridge, T.C., "What Knowledge Is Important to a Software Professional?", IEEE Computer, 33(5), 1998, pp.44-50.

12. Lyytinen, K. and Yoo, Y., "Issues and Challenges in Ubiquitous Computing," Communications of the ACM, 45(12), 2002, pp. 63-65.

13. Markus, M. L. and Robey, D., "Information Technology and Organizational Change," Management Science, 34(5), 1988, pp. 583-598.

14. Milliken, J. and Barnes, L. P., "Teaching and Technology in Higher Education: Student Perceptions and Personal Reflections", Computers \& Education, 39(3), 2002, pp. 223-235.

15. Straub, D. W., "Research Commentary: Transformational Issues in Researching IS and Net-Enabled Organizations," Information Systems Research, 12(4), 2001, pp. 337-345.

16. Tennyson, R.D., "Defining Core Competencies of an Instructional Technologist", Computers in Human Behavior, 17 (3), 2001, pp. 355-361.

17. Varshney, U., Vetter, R. J., and Kalakota, R., “Mobile Commerce: A New Frontier,” IEEE Computer, October, 2000, pp. 32-38.

18. Watson, R. T., Pitt L. F., Berthon, P., and Zinkhan, G. M., "U-Commerce: Extending the Universe of Marketing," Journal of the Academy of Marketing Science, 30(4), 2002, pp. 329-343.

19. Wheeler, C., "NEBIC: A Dynamic Capabilities Theory for Assessing Net-Enablement," Information Systems Research, 13(2), 2002, pp.125-146.

20. Wu, J. H., Chen, Y. C. and Lin, H. H., "Developing a Set of Management Needs for IS Managers: A Study of Necessary Management Activities and Skills", Information \& Management, 41(4), 2004, pp. 413-429.

21. Wu, J. H. and Hsia, T. L., "Analysis of E-Commerce Innovation and Impact: a Hypercube Model," Electronic Commerce Research and Applications, 3(4), 2004, pp. 389-404.

22. Zwass, V. (2003), "Electronic Commerce and Organizational Innovation: Aspects and Opportunities," International Journal of Electronic Commerce, 7(3), 2003, pp. 7-37. 